\title{
The results of transperineal versus transrectal prostate biopsy: a systematic review and meta-analysis
}

\author{
Peng-Fei Shen ${ }^{1, *}$, Yu-Chun Zhu ${ }^{1, *}$, Wu-Ran Wei ${ }^{1}$, Yong-Zhong $\mathrm{Li}^{2}$, Jie Yang ${ }^{1}$, Yu-Tao Li ${ }^{1}$, Ding-Ming Li $^{1}$, \\ Jia Wang ${ }^{1}$ and Hao Zeng ${ }^{1}$
}

This systematic review was performed to compare the efficacy and complications of transperineal (TP) vs. transrectal (TR) prostate biopsy. A systematic research of PUBMED, EMBASE and the Cochrane Library was performed to identify all clinical controlled trials on prostate cancer ( $\mathrm{PCa}$ ) detection rate and complications achieved by TP and TR biopsies. Prostate biopsies included sextant, extensive and saturation biopsy procedures. All patients were assigned to a TR group and a TP group. Subgroup analysis was performed according to prostate-specific antigen (PSA) levels and digital rectal examination (DRE) findings. The Cochrane Collaboration's RevMan 5.1 software was used for the meta-analysis. A total of seven trials, including three randomized controlled trials (RCTs) and four casecontrol studies (CCS), met our inclusion criteria. There was no significant difference in the cancer detection rate between the sextant TR and TP groups (risk difference (RD), $-0.02 ; 95 \%$ confidence interval $(\mathrm{Cl}),-0.08-0.03 ; P=0.34$ ). Meta-analysis for RCTs combined with CCS showed that there was no difference in the cancer detection rate between the extensive TR and TP group (RD, $-0.01 ; 95 \% \mathrm{Cl},-0.05-0.04 ; P=0.81)$. There was no significant difference in PCa detection rate between the saturation TR and TP approaches ( $31.4 \%$ vs. $25.7 \%$, respectively; $P=0.3$ ). There were also no significant differences in cancer detection between the TR and TP groups in each subgroup. Although the data on complications were not pooled for the meta-analysis, no significant difference was found when comparing TR and TP studies. TR and TP biopsies were equivalent in terms of efficiency and related complications. TP prostate biopsy should be an available and alternative procedure for use by urologists.

Asian Journal of Andrology (2012) 14, 310-315; doi:10.1038/aja.2011.130; published online 21 November 2011

Keywords: prostate biopsy; prostate cancer; transperineal; transrectal

\section{INTRODUCTION}

Within the past two decades, improvements in the early detection of prostate cancer $(\mathrm{PCa})$ have been achieved. ${ }^{1,2}$ The main screening tools that are used to look for evidence of PCa include digital rectal examination (DRE), serum prostate-specific antigen (PSA) and transrectal ultrasonography (TRUS). ${ }^{3,4}$ The use of PSA is accepted widely and is initiated by the screener. ${ }^{1,2}$ The diagnosis of PCa depends on the presence of adenocarcinoma in operative specimens, prostate biopsy cores or aspiration-needle cytology. Since the introduction of the systematic sextant transrectal (TR) prostate biopsy with TRUS, it has become an accepted, routinely performed technique for PCa detection. ${ }^{5}$ Extended and saturation biopsy cores are respectively performed at first and repeat biopsies. These techniques have been reported to enhance the cancer detection rate. ${ }^{6}$

TR biopsy is the most common procedure for PCa detection; the transperineal (TP) approach is rarely used in the United States. ${ }^{7}$ Although TP prostate biopsy is performed by some institutions, especially in Europe and Asia, it has been progressively neglected, and today, is far less common. ${ }^{8-10}$ A prospective study showed a high $\mathrm{PCa}$ detection rate with TP prostate biopsy, which was superior to the detection rate previously reported for TR biopsy techniques. ${ }^{9}$
Many studies were designed to demonstrate this point. ${ }^{11-13}$ Despite these trials, the optimum methodology for prostate biopsy to detect cancer lesions remains to be defined.

We conducted this systematic review to compare the efficacy and complications of TR to TP prostate biopsy by collecting all published randomized or non-randomized controlled trials (RCTs or nonRCTs) that were conducted using these two techniques. To our best knowledge, this is the first systematic review and meta-analysis to compare TP and TR prostate biopsies.

\section{MATERIAL AND METHODS}

We searched the following databases: PUBMED, EMBASE, the Cochrane Central Register of Controlled Trials and the Cochrane Database of Systematic Review (updated to 21 May 2011). The search process was designed to initially find all trials involving the following terms: 'prostate cancer', 'cancer of prostate', 'carcinoma of prostate', 'prostatic neoplasm', 'detection', 'biopsy', 'prostate biopsy', 'transrectal', 'transperineal', 'transrectal approach' and 'transperineal approach'. Reference lists from identified reports, reviews and other relevant publications were also searched. Computer searches were supplemented with a manual search. RCTs, quasi-randomized

${ }^{1}$ Department of Urology, West China Hospital, Sichuan University, Chengdu 610041, China and ${ }^{2}$ Department of Ultrasonography, West China Hospital, Sichuan University, Chengdu 610041, China

* These authors contributed equally to this work.

Correspondence: Dr H Zeng (cdhx510@126.com) and Dr J Wang (cdhx510@foxmail.com)

Received: 4 July 2011; Revised: 27 July 2011; Accepted: 11 August 2011; Published online: 21 November 2011 
controlled studies, case-control studies and cohort studies were included when they compared the efficacy and safety of TP and TR prostate biopsies. Two authors independently screened all citations and abstracts identified by the search strategy to identify eligible studies. Articles in all languages were sought, and non-English papers were translated before assessment.

Adult males who had elevated PSA levels, abnormal DRE findings and/or abnormal TRUS findings were enrolled in the review. Some patients who previously underwent prostate biopsy and those who underwent saturation rebiopsy were also included. Patients with a previous history of $\mathrm{PCa}$, acute prostatitis or proven urinary tract infection were excluded. Prostate biopsy was performed under the guidance of ultrasound and included sextant biopsy, extensive biopsy and saturation biopsy. All patients were divided into two groups: a TR group and a TP group. Subgroup analysis was performed according to different PSA levels and DRE findings.

Data were extracted independently by two authors using a predesigned data extraction form. Data extraction included data source, eligibility, methods, participant characteristics, interventions and results. Then the two authors met to synthesize their findings and the information subsequently was entered into the Review Manager 5.1 (RevMan 5.1, available from http://www.cochrane.org/, 25 May 2011). Any discrepancies were resolved by consultation with the third reviewer. The quality of included RCTs was assessed according to the Cochrane Collaboration Reviewers' Handbook including the assessment of the generation of randomization sequences, allocation concealment, the description of withdrawals and dropouts, and intentionto-treat analysis. ${ }^{14}$ The blinding method was not analysed in this review, because it was not suitable for surgery-related clinical trials. The included non-RCTs were assessed with the Newcastle-Ottawa Scale. Scores of 5-9 were defined as high quality, and a score $<5$ was defined as low quality. ${ }^{15}$

A meta-analysis was performed using RevMan 5.1. For all eligible studies, dichotomous data were presented as risk difference (RD) with 95\% confidence intervals (CIs) for comparisons between TR and TP approaches. The Mantel-Haenszel-type method was used to estimate the pooled RD for all strata. The heterogeneity in the meta-analysis related to the variation in study outcomes was evaluated by the $I$ square test, which was the percentage of variation across studies due to heterogeneity rather than chance. As the included studies were heterogeneous (the design, included patients, country of origin, etc.), the meta-analysis was performed using a random-effects method, which allowed the outcomes to vary in a normal distribution between studies. The 'events' in the figures represented the patients with PCa lesions. Additionally, sensitivity analysis should be performed if low-quality trials were included.

\section{RESULTS}

\section{Description of studies}

In total, 468 studies were identified from the electronic database and manual search. After assessment, we identified seven trials-three $\mathrm{RCTs}^{18-20}$ and four case-control studies $(\mathrm{CCS})^{12,16,17,21}$ - that met our inclusion criteria. The other 461 studies were excluded from the review for the following reasons: irrelevant subjects $(n=426)$, as determined by screening titles and abstracts, uninteresting interventions $(n=28)$ and ineligible full-text articles $(n=7)$. Quality assessment showed that all CCS were deemed as high quality, and all RCTs were inadequate in terms of sequence generation and allocation concealment. These trials were divided into three groups: the sextant biopsy group (two studies), ${ }^{12,16}$ extensive biopsy group (four studies) ${ }^{17-20}$

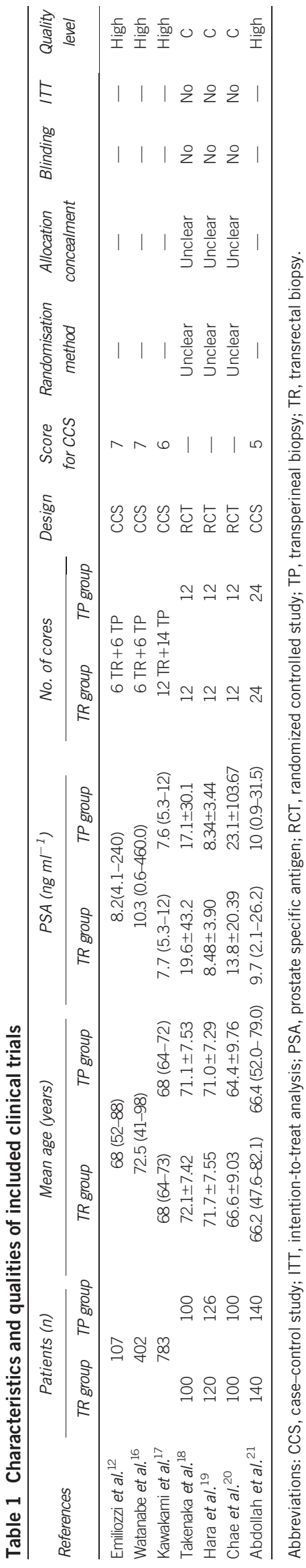




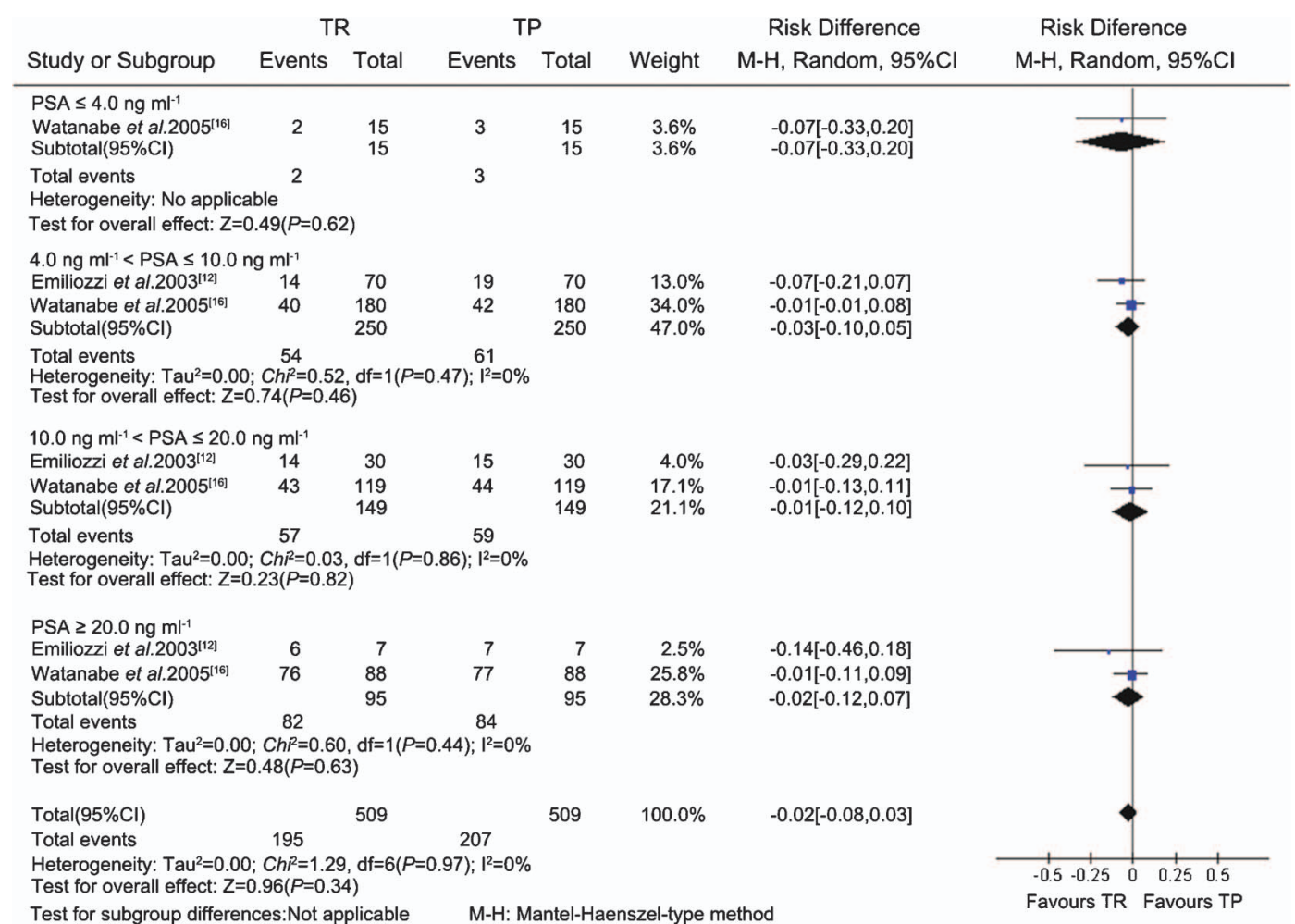

Figure 1 Subgroup analysis of different PSA levels between the TR and TP groups (sextant biopsy). Cl, confidence interval; PSA, prostate specific antigen; TP, transperineal; TR, transrectal.

and saturation biopsy group (one study). ${ }^{21}$ The sextant biopsy group included 509 patients; the extensive biopsy group, 1429 patients; and the saturation group, 280 patients. Patients in three CCS underwent TR prostate biopsy and TP prostate biopsy simultaneously. The characteristics and qualities of the included trials are presented in Table $\mathbf{1 .}$

\section{Sextant prostate biopsy}

In the two case-control sextant biopsy studies, ${ }^{12,16}$ a combination of sextant TR and TP prostate biopsies was performed as a new extensive biopsy approach. The effects of the two procedures were compared by the authors. The data from the included studies were pooled in the metaanalysis. There was no significant difference in cancer detection rate between the sextant TR (195/509) and TP (207/509) groups, for a total of 509 patients (RD, $-0.02 ; 95 \% \mathrm{CI},-0.08-0.03 ; P=0.34$ ) (Figure 1). Subgroup analysis was performed according to different PSA levels $\left(\mathrm{PSA} \leqslant 4 \mathrm{ng} \mathrm{ml}^{-1}, \quad 4 \mathrm{ng} \mathrm{ml}^{-1}<\mathrm{PSA} \leqslant 10 \mathrm{ng} \mathrm{ml}^{-1}, \quad 10 \mathrm{ng} \mathrm{ml}^{-1}<\mathrm{PSA} \leqslant\right.$ $20 \mathrm{ng} \mathrm{ml}^{-1}$ and PSA $>20 \mathrm{ng} \mathrm{ml}^{-1}$ ) and DRE findings (positive/negative). There were no significant differences in cancer detection between the TR and TP groups for any subgroup (Figures 1 and 2).

\section{Extensive prostate biopsy}

The data related to extensive prostate biopsy were available from one $\mathrm{CCS}^{17}$ and three RCTs. ${ }^{18-20}$ Heterogeneity was assessed using the I-square analysis. Meta-analysis of the RCTs and CCS demonstrated that there was no difference in cancer detection rate between the TR (364/ $1103)$ and TP (372/1109) groups (RD, -0.01 ; 95\% CI, $-0.05-0.04$;

\begin{tabular}{|c|c|c|c|c|c|c|c|}
\hline \multirow[b]{2}{*}{ Study or subgroup } & \multicolumn{2}{|l|}{ TR } & \multicolumn{2}{|c|}{ TP } & \multicolumn{2}{|r|}{ Risk Difference } & \multirow{2}{*}{$\begin{array}{l}\text { Risk Difference } \\
\mathrm{M}-\mathrm{H}, \text { Random, } 95 \% \mathrm{Cl}\end{array}$} \\
\hline & Events & Total & Events & Total & Weight & $\mathrm{M}-\mathrm{H}$, Random, $95 \% \mathrm{Cl}$ & \\
\hline \multicolumn{8}{|l|}{ Positive } \\
\hline Emiliozzi et al.2003[112] & 21 & 26 & 25 & 26 & $40.6 \%$ & $-0.15[-0.32,0.01]$ & \\
\hline Watanabe et al.2005 & 100 & 130 & 100 & 130 & $59.4 \%$ & $0.00[-0.10,0.10]$ & \\
\hline Subtotal $(95 \% \mathrm{Cl})$ & & 156 & & 156 & $100.0 \%$ & $-0.06[-0.21,0.09]$ & \\
\hline \multicolumn{8}{|c|}{$\begin{array}{l}\text { Total events } \quad 121 \\
\text { Heterogeneity: } \operatorname{Tau}^{2}=0.01 ; C^{2}=2.46, \mathrm{df}=1(P=0.12) ; l^{2}=59 \% \\
\text { Test for overall effect: } Z=0.81(P=0.42)\end{array}$} \\
\hline \multicolumn{8}{|l|}{ Negative } \\
\hline Emiliozzi et al.2003 & 13 & & 16 & 81 & $26.6 \%$ & $-0.04[-0.15,0.08]$ & \\
\hline Watanabe et al.2005 & 61 & 272 & 66 & 272 & $73.4 \%$ & $-0.02[-0.09,0.05]$ & \\
\hline Subtotal $(95 \% \mathrm{Cl})$ & & 353 & & 353 & $100.0 \%$ & $-0.02[-0.08,0.04]$ & \\
\hline \multicolumn{8}{|c|}{$\begin{array}{lc}\text { Total events } & 74 \\
\text { Heterogeneity: } T a u^{2}=0.00 ; C h{ }^{2}=0.07, d f=1(P=0.79) ; I^{2}=0 \% \\
\text { Test for overall effect: } Z=0.75(P=0.45)\end{array}$} \\
\hline \multirow{2}{*}{\multicolumn{8}{|c|}{$\begin{array}{l}\text { Test for subgroup differences: Not applicable } \\
\text { M-H: Mantel-Haenszel-type method }\end{array}$}} \\
\hline & e method & & & & & & 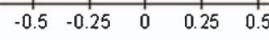 \\
\hline
\end{tabular}

Figure 2 Subgroup analysis of different DRE findings between the TR and TP groups (sextant biopsy). Cl, confidence interval; DRE, digital rectal examination; $\mathrm{TP}$, transperineal; TR, transrectal. 


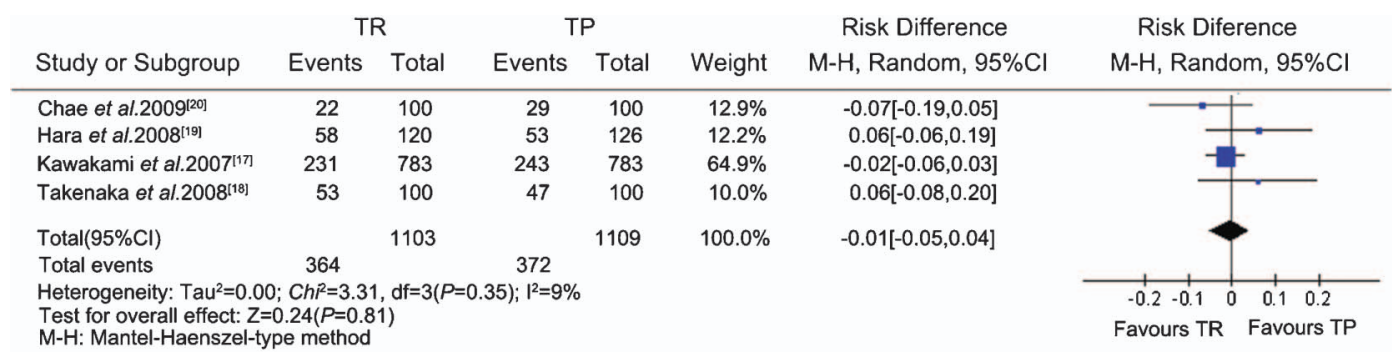

Figure 3 Total PCa detection rate for the TR and TP groups (extensive biopsy). Cl, confidence interval; PCa, prostate cancer; TP, transperineal; TR, transrectal.

\begin{tabular}{|c|c|c|c|c|c|c|c|}
\hline \multirow[b]{2}{*}{ Study or Subgroup } & \multicolumn{2}{|c|}{ TR } & \multicolumn{2}{|c|}{ TP } & \multirow[b]{2}{*}{ Weight } & Risk Difference & \multirow{2}{*}{$\begin{array}{c}\text { Risk Diference } \\
\text { M-H, Random, } 95 \% \mathrm{Cl}\end{array}$} \\
\hline & Events & Total & Events & Total & & M-H, Random, 95\%Cl & \\
\hline \multicolumn{8}{|l|}{$\mathrm{PSA} \leq 4.0 \mathrm{ng} \mathrm{ml}^{-1}$} \\
\hline Takenaka et al.2008 $8^{[18]}$ & 0 & 2 & 2 & 2 & $46.3 \%$ & $-1.00[-1.60,-0.40]$ & \\
\hline Subtotal $(95 \% \mathrm{Cl})$ & & 17 & & 18 & $100.0 \%$ & $-0.43[-1.49,0.63]$ & \\
\hline \\
\hline \multirow{2}{*}{\multicolumn{8}{|c|}{$\begin{array}{l}\text { Heterogeneity: } \operatorname{Tau}^{2}=0.54 ; C h \mathrm{P}^{2}=11.77, \mathrm{df}=1(P=0.0006) ;\left.\right|^{2}=92 \% \\
\text { Test for overall effect: } Z=0.79(P=0.43)\end{array}$}} \\
\hline & & & & & & & \\
\hline \multicolumn{8}{|c|}{$4.0 \mathrm{ng} \mathrm{ml}^{-1}<\mathrm{PSA} \leq 10.0 \mathrm{ng} \mathrm{ml}^{-1}$} \\
\hline Chae et al.2009:20] & 10 & 49 & 8 & 55 & $35.9 \%$ & $0.06[-0.09,0.20]$ & $\rightarrow$ \\
\hline Hara et al.2008 & 38 & 89 & 34 & 94 & $38.4 \%$ & $0.07[-0.08,0.21]$ & $=$ \\
\hline Takenaka et al.2008 ${ }^{[18]}$ & 20 & 57 & 22 & 61 & $25.7 \%$ & $-0.01[-0.18,0.16]$ & \\
\hline Subtotal $(95 \% \mathrm{Cl})$ & & 195 & & 210 & $100.0 \%$ & $0.04[-0.04,0.13]$ & $\rightarrow$ \\
\hline \multirow{2}{*}{\multicolumn{8}{|c|}{$\begin{array}{l}\text { Total events } \\
\text { Heterogeneity: } T^{2} u^{2}=0.54 ; C h i^{2}=0.50, d f=2(P=0.78) ;\left.\right|^{2}=0 \%\end{array}$}} \\
\hline & & & & & & & \\
\hline \multicolumn{8}{|c|}{ Test for overall effect: $Z=0.97(P=0.33)$} \\
\hline \multicolumn{8}{|l|}{$\mathrm{PSA}>10.0 \mathrm{ng} \mathrm{ml}^{-1}$} \\
\hline Chae et al.2009 ${ }^{[20]}$ & 18 & 36 & 14 & 29 & $30.7 \%$ & $0.02[-0.23,0.26]$ & - \\
\hline Hara et al.2008 & 20 & 31 & 19 & 32 & $31.3 \%$ & $0.05[-0.19,0.29]$ & \\
\hline Takenaka et al.2008 ${ }^{[18]}$ & 33 & 41 & 23 & 47 & $38.0 \%$ & $0.32[0.13,0.50]$ & \\
\hline Subtotal(95\%Cl) & & 108 & & 108 & $100.0 \%$ & $0.14[-0.06,0.34]$ & \\
\hline \multirow{2}{*}{\multicolumn{8}{|c|}{$\begin{array}{l}\text { Total events } \\
\text { Heterogeneity: } \operatorname{Tau}^{2}=0.02 ; C h h^{2}=4.79, \mathrm{df}=2(P=0.09) ;\left.\right|^{2}=58 \%\end{array}$}} \\
\hline & & & & & & & \\
\hline \multicolumn{8}{|c|}{ Test for overall effect: $Z=1.39(P=0.16)$} \\
\hline \multicolumn{8}{|c|}{ M-H: Mantel-Haenszel-type method } \\
\hline & & & & & & & 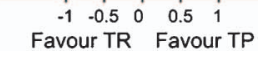 \\
\hline
\end{tabular}

Figure 4 Subgroup analysis of different PSA levels between the TR and TP groups (extensive biopsy). Cl, confidence interval; PSA, prostate specific antigen; TP, transperineal; TR, transrectal.

$P=0.81$ ) (Figure 3). Subgroup analysis also showed that there were no significant differences in the cancer detection rate between the TR and TP groups in each subgroup according to different PSA levels (PSA $\leqslant 4 \mathrm{ng} \mathrm{ml}^{-1}, 4 \mathrm{ng} \mathrm{ml}^{-1}<\mathrm{PSA} \leqslant 10 \mathrm{ng} \mathrm{ml}^{-1}$ and PSA $>10 \mathrm{ng} \mathrm{ml}^{-1}$ ) and DRE findings (positive/negative) (Figures 4 and 5).

\section{Saturation prostate biopsy}

Only one CCS compared the rate of PCa detection between the TR and TP approaches in men undergoing a saturation (24-core) prostate rebiopsy. ${ }^{21}$ We did not pool the data for a meta-analysis. The total PCa detection rate was approximately $28.6 \%$. There was no statistically

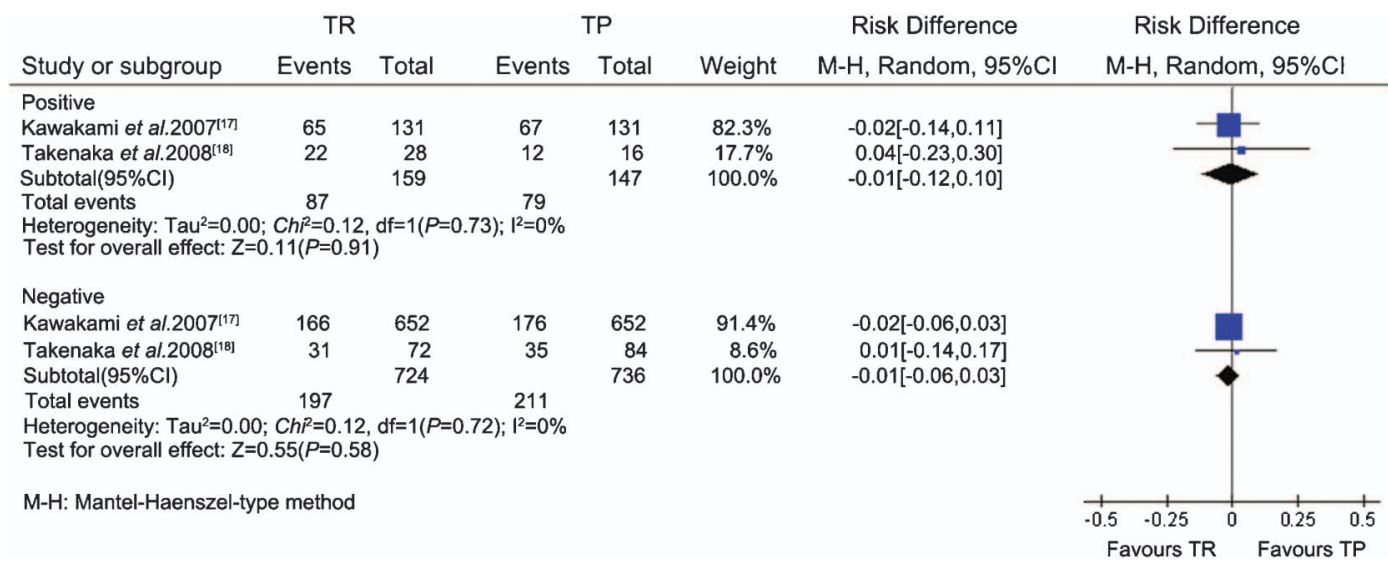

Figure 5 Subgroup analysis of different DRE findings between the TR and TP groups (extensive biopsy). Cl, confidence interval; DRE, digital rectal examination; $\mathrm{TP}$, transperineal; TR, transrectal. 
significant difference in the PCa detection rate between the TR and TP approach ( $31.4 \%$ vs. $25.7 \%$, respectively; $P=0.3)$.

\section{Complications}

Complications were reported in all included studies except for one trial conducted to study saturation biopsies. ${ }^{21}$ The most common complication was haematuria, especially macrohaematuria. Even though adverse event data were not pooled for the meta-analysis, no significant difference was found in the analysed studies. For example, in Emiliozzi's study, ${ }^{12}$ complications included temporary haematuria in 33 patients $(31 \%)$, mild post-biopsy perineal discomfort in 7 patients $(6 \%)$ and haematospermia in 58 patients (54\%). In Hara's study, ${ }^{19}$ complications were examined separately for the TR and TP groups, with additional discrimination between major complications (fever, rectal bleeding and urinary retention) and minor complications (haematuria and haematospermia), but no significant differences in the number of complications were found between the groups.

\section{DISCUSSION}

Prostate biopsy plays an important role in diagnosing $\mathrm{PCa}$, confirming the grade of cancer and stratifying tumour aggressiveness. In most patients, management can be decided based on biopsy data, supplemented by other data, such as patient status and PSA level. ${ }^{22}$ Therefore, prostate biopsy lies at the heart of PCa diagnosis and management. ${ }^{23}$ As PCa is often multifocal and limited to small lesions, the detection rate may be affected by different biopsy procedures and the number of samples. We therefore compared the efficacy of TR and TP biopsies according to the number of cores in this systematic review.

Our comparisons between the TR and TP approaches showed no significant difference in the overall cancer detection rate. Moreover, we also found that the PCa detection rates were similar, in terms of subgroup analysis between the TP and TR groups, regardless of PSA levels and DRE findings. This suggested that the TP approach was as efficient as the TR approach.

Theoretically, because the cores of the TP approach are directed longitudinally to the peripheral zone and the anterior part of the prostate, the TP approach should detect more PCa than the TR approach. ${ }^{21}$ Some investigators thought that inclusion of cores from the lateral part of the prostate could explain the higher cancer diagnosis achieved with this type of biopsy. ${ }^{12,24}$ However, there was no significant difference in core positivity rates at the peripheral zone, transition zone, apex or any other site between the TP group and TR group in two RCTs. ${ }^{18,19}$ Other factors that may affect the cancer detection rate included the fact that the biopsy was directed towards suspicious areas of the prostate and not performed according to a systematic technique under the guidance of ultrasound; furthermore, TP biopsy may require a longer training period.

As to complications, although some studies could not distinguish between the TR and TP approaches in terms of the causes of complications, no significant differences were found in the incidence of major or minor complications between the two approaches in other studies. Therefore, TP biopsy is a safe procedure for PCa detection.

Our systematic review has several limitations. Because our database included a limited number of randomized studies, case-control studies were collected and their results might have introduced considerable bias. However, we used the appropriate methods to evaluate the quality of studies included in our meta-analysis. Many factors could affect the rate of PCa detection, such as the number of cores in different zones of the prostate, total prostate volume and the proficiency of a particular physician, but these were not considered in our subgroup analysis. We searched the relative literature in electronic databases without language restriction, but we were inevitably unable to find all the studies concerning TR and TP biopsies in other languages. This may have introduced language bias and publication bias.

As we described above, TR and TP biopsies were equivalent in terms of efficiency and complications $(P=0.34$ for sextant biopsy and $P=0.81$ for extensive biopsy). Therefore, TP prostate biopsy should be available to urologists as an alternative procedure. Because of the limited methodological quality of the included studies, additional multicentre RCTs are needed.

\section{AUTHOR CONTRIBUTIONS}

PFS, YCZ, JW and HZ conceived the study, participated in its design, and coordinated and drafted the manuscript. PFS, YCZ, WRW, YZL, JY, YTL and DML collected the data. PFS, JW and HZ performed the statistical analysis. PFS, YCZ, JW and HZ participated in critical revision of the manuscript. All authors read and approved the final manuscript.

\section{COMPETING FINANCIAL INTERESTS}

The authors have no financial or commercial interests related to the study.

\section{ACKNOWLEDGMENTS}

This review was supported by Nationnal Natural Science Foundation of China (NSFC 81172439).

1 Schröder FH, Hugosson J, Roobol MJ, Tammela TL, Ciatto S et al. Screening and prostate cancer mortality in a randomized European study. N Engl J Med 2009; 360: 1320-8

2 Andriole GL, Crawford ED, Grubb RL3rd, Buys SS, Chia D et al. Mortality results from a randomized prostate-cancer screening trial. N Engl J Med 2009; 360: 1310-9.

3 Chun FK, Epstein JI, Ficarra V, Freedland SJ, Montironi R et al. Optimizing performance and interpretation of prostate biopsy: a critical analysis of the literature. Eur Urol 2010; 58: 851-64.

4 Borley N, Feneley MR. Prostate cancer: diagnosis and staging. Asian J Androl 2009; 11: 74-80.

5 Hodge KK, McNeal JE, Terris MK, Stamey TA. Random systematic versus directed ultrasound guided transrectal core biopsies of the prostate. J Urol 1989; 142: 71-5.

6 Scattoni V, Zlotta A, Montironi R, Schulman C, Rigatti P et al. Extended and saturation prostatic biopsy in the diagnosis and characterisation of prostate cancer: a critical analysis of the literature. Eur Urol 2007; 52: 1309-22.

7 Shandera KC, Thibault GP, Deshon GE Jr. Variability in patient preparation for prostate biopsy among American urologists. Urology 1998; 52: 644-6.

8 Vis AN, Boerma MO, Ciatto S, Hoedemaeker RF, Schröder FH et al. Detection of prostate cancer: a comparative study of the diagnostic efficacy of sextant transrectal versus sextant transperineal biopsy. Urology 2000; 56: 617-21.

9 Emiliozzi P, Longhi S, Scarpone P, Pansadoro A, DePaula F et al. The value of a single biopsy with 12 transperineal cores for detecting prostate cancer in patients with elevated prostate specific antigen. J Urol 2001; 166: 845-50.

10 Kang SG, Tae BS, Min SH, Ko YH, Kang SH et al. Efficacy and cost analysis of transrectal ultrasound-guided prostate biopsy under monitored anesthesia. Asian $J$ Androl 2011; 13: 724-7.

11 Kojima M, Hayakawa T, Saito T, Mitsuya H, Hayase Y. Transperineal 12-core systematic biopsy in the detection of prostate cancer. Int J Urol 2001; 8: 301-7.

12 Emiliozzi P, Corsetti A, Tassi B, Federico G, Martini M et al. Best approach for prostate cancer detection: a prospective study on transperineal versus transrectal six-core prostate biopsy. Urology 2003; 61: 961-6.

13 Saredi G, Sighinolfi MC, Fidanza F, de Stefani S, Micali S et al. Does needle calibre affect pain and complication rates in patients undergoing transperineal prostate biopsy? A prospective, randomized trial. Asian J Androl 2009; 11: 678-82.

14 Higgins JPT, Green S (ed). Cochrane Handbook for Systematic Reviews of Interventions. Version 5.1.0 [updated March 2011]. The Cochrane Collaboration, 2011. Available from:http://www.cochrane-handbook.org.

15 Wells GA, Shea B, O'Connell D. The Newcastle-Ottawa Scale (NOS) for assessing the quality of nonrandomized studies in meta-analyses. Ottawa, ON, 
CanadaOttawa Health Research InstituteAvailable from: http://www.ohri.ca/ programs/clinical_epidemiology/oxford.asp.

16 Watanabe M, Hayashi T, Tsushima T, Irie S, Kaneshige T et al. Extensive biopsy using a combined transperineal and transrectal approach to improve prostate cance detection. Int J Urol 2005; 12: 959-63.

17 Kawakami S, Yamamoto S, Numao N, Ishikawa Y, Kihara K et al. Direct comparison between transrectal and transperineal extended prostate biopsy for the detection of cancer. Int J Urol 2007; 14: 719-24.

18 Takenaka A, Hara R, Ishimura T, Fujii T, Jo $\mathrm{Y}$ et al. A prospective randomized comparison of diagnostic efficacy between transperineal and transrectal 12-core prostate biopsy. Prostate Cancer Prostatic Dis 2008; 11: 134-8.

19 Hara R, Jo Y, Fujii T, Kondo N, Yokoyoma T et al. Optimal approach for prostate cance detection as initial biopsy: prospective randomized study comparing transperineal versus transrectal systematic 12-core biopsy. Urology 2008; 71: 191-5.
20 Chae Y, Kim YJ, Kim T, Yun SJ, Lee SC et al. The comparison between transperineal and transrectal ultrasound-guided prostate needle biopsy. Korean J Urol 2009; 50: 119-24.

21 Abdollah F, Novara G, Briganti A, Scattoni V, Raber M et al. Trans-rectal versus transperineal saturation rebiopsy of the prostate: is there a difference in cancer detection rate? Urology 2011; 77: 921-5.

22 Dai B, Ye DW, Kong YY, Shen YJ, Wang BH. Individualized prostate biopsy strategy for Chinese patients with different prostate-specific antigen levels. Asian J Androl 2008 10: 325-31.

23 Raja J, Ramachandran N, Munneke G, Patel U. Current status of transrectal ultrasound-guided prostate biopsy in the diagnosis of prostate cancer. Clin Radiol 2006; 61: 142-53.

24 Gore JL, Shariat SF, Miles BJ, Kadmon D, Jiang N et al. Optimal combinations of systematic sextant and laterally directed biopsies for the detection of prostate cancer. J Urol 2001; 165: 1554-9. 